\title{
An essential role of a ferritin-like protein in acid stress tolerance of Listeria monocytogenes
}

\author{
Dorota Milecka $\cdot$ Anna Samluk $\cdot$ Katarzyna Wasiak \\ Agata Krawczyk-Balska
}

Received: 18 May 2014 / Revised: 1 September 2014 / Accepted: 22 October 2014 / Published online: 29 October 2014

(C) The Author(s) 2014. This article is published with open access at Springerlink.com

\begin{abstract}
The expression of ten genes of Listeria monocytogenes previously identified as penicillin G-inducible was transcriptionally analyzed in the presence of $0.5 \mathrm{M} \mathrm{KCl}$, $\mathrm{pH} 5.0$ and $42{ }^{\circ} \mathrm{C}$. This study revealed that all the genes are upregulated by osmotic stress, seven by acid stress and four by temperature stress conditions. The contribution of a gene encoding a ferritin-like protein (fri), a two-component phosphate-response regulator $(p h o P)$ and an AraC/XylS family transcription regulator $(\operatorname{axy} R)$ to temperature, acid and osmotic stress tolerance was further examined by analysis of nonpolar deletion mutants. This revealed that a lack of PhoP or AxyR does not affect the ability to grow under the tested stress conditions. However, the $\boldsymbol{\Delta}$ fri strain showed slightly delayed growth under osmotic and clearly impaired growth under acid stress conditions, indicating an important role of the ferritin-like protein in acid stress tolerance.
\end{abstract}

Keywords Listeria monocytogenes · Acid stress . Ferritin-like protein

\section{Introduction}

Listeria monocytogenes is a foodborne Gram-positive pathogen that causes rare but severe disease in humans and animals. This bacterium can adapt to survive in different environmental conditions including a wide range

Communicated by Jorge Membrillo-Hernández.

D. Milecka · A. Samluk · K. Wasiak · A. Krawczyk-Balska ( $₫)$

Department of Applied Microbiology, Faculty of Biology, University of Warsaw, Miecznikowa 1, 02-096 Warsaw, Poland e-mail: akra@biol.uw.edu.pl of temperatures $\left(0-45^{\circ} \mathrm{C}\right)$, relatively low $\mathrm{pH}$ values, high concentrations of salt and the presence of a high concentration of $\beta$-lactam antibiotics that are antibiotics of choice in the treatment of listeriosis. The adaptive abilities allow the wide distribution of $L$. monocytogenes in the natural environment, survival of food processing and rapidly changing conditions encountered during gastrointestinal passage and subsequent stages of infection and antibiotic therapy (Vazquez-Boland et al. 2001; Hof 2003; Gandhi and Chikindas 2007). Taking into account the importance of the adaptive abilities of $L$. monocytogenes, the primary goals of much research effort focus on identifying genes playing an important role in stress tolerance. So far, the best documented role in the response of $L$. monocytogenes to stressful conditions has been established for genes coding for sigma factors and two-component signal transduction systems that have highlighted the importance of regulator proteins in the adaptation of L. monocytogenes (Ferreira et al. 2001; Williams et al. 2005; Raimann et al. 2009). What is worth note is that individual regulator proteins and sigma factors often play an important role in response to more than one stress factor (Cotter et al. 1999, 2002; Ferreira et al. 2001; Kallipolitis et al. 2003; Begley et al. 2006; Raimann et al. 2009). The characterization of the variation of $L$. monocytogenes gene expression patterns in different harmful conditions has also been the subject of intensive study since it could help to elucidate the mechanisms of L. monocytogenes tolerance to different stresses. Interestingly, a recent transcriptomic study showed large overlap between the cefuroxime stimulon and genes known to be induced in L. monocytogenes in blood and during intracellular infection which suggests that the pattern of transcriptional changes related to cell-envelope-stress response overlaps in different stress conditions (Nielsen et al. 2012). Recently, we identified ten genes of L. monocytogenes 
whose expression was upregulated in response to penicillin $G$ pressure (Krawczyk-Balska et al. 2012). Two of these, namely $p h o P$ and $a x y R$, encode regulatory proteins. Gene phoP encodes a two-component phosphate-response regulator, and $\operatorname{axy} R$ gene encodes a transcriptional regulator from the AraC/XylS regulator family (Williams et al. 2005; Sabet et al. 2008). Among the identified genes was also fri encoding an iron-binding ferritin-like protein (Fri) that belongs to the Dps (DNA-binding proteins from starved cells) family of proteins (Haikarainen and Papageorgiou 2010). Fri of L. monocytogenes is not a sensu stricto regulator protein. However, it contributes to virulence and plays a role in protection against multiple stresses. Furthermore, in the fri mutant strain, significant changes in the content of the global regulators catabolite control protein A (CcpA) and anti-sigma $\mathrm{B}$ factor (RsbW) were observed, thus suggesting that Fri has a global impact on the L. monocytogenes regulatory network (Dussurget et al. 2005; Olsen et al. 2005). Susceptibility studies showed that Fri is a mediator of $\beta$-lactam tolerance and innate resistance to cephalosporins, and that the protein plays a critical role in the control of L. monocytogenes cell envelope structure and stability under $\beta$-lactam pressure, whereas PhoP and AxyR do not influence susceptibility and tolerance to this class of antibiotics (Krawczyk-Balska et al. 2012; Krawczyk-Balska and Lipiak 2013).

The aim of the present study was to determine how the transcription of previously identified penicillin G-inducible genes changes under temperature, acid and osmotic pressure and to examine whether fri, phoP and $\operatorname{axy} R$ genes play a role in the adaptation of $L$. monocytogenes to these stress conditions.

\section{Materials and methods}

Bacterial strains, media, plasmids and DNA techniques

The L. monocytogenes EGD (serotype 1/2a) wild-type strain was kindly provided by S.J. Foster, University of Sheffield, United Kingdom. Isogenic EGD $\Delta p h o P$ and EGD $\triangle a x y R$ deletion mutants were constructed in a previous study (Krawczyk-Balska et al. 2012), and the isogenic EGD $\Delta$ fri deletion mutant was a generous gift from Hanne Ingmer, Royal Veterinary and Agricultural University, Denmark. L. monocytogenes strains were grown in brain heart infusion (BHI) broth medium (Oxoid).

\section{Total RNA isolation}

For RNA isolation, a culture of wild-type L. monocytogenes EGD was inoculated and incubated overnight at $37^{\circ} \mathrm{C}$. The following morning, the culture was diluted 1:50 into fresh medium. The culture was grown at $37{ }^{\circ} \mathrm{C}$ with aeration to an $\mathrm{OD}_{600}$ of 0.2. At this point, for osmotic stress and acid stress treatments, the cells were harvested by centrifugation and then resuspended in $\mathrm{BHI}$ broth containing $0.5 \mathrm{M} \mathrm{KCl}$ or resuspended in $\mathrm{BHI}$ broth adjusted to $\mathrm{pH} 5$ with $\mathrm{HCl}$, respectively, and incubation was continued for $90 \mathrm{~min}$ at $37^{\circ} \mathrm{C}$. For temperature stress treatment, once the refreshed culture attained an $\mathrm{OD}_{600}$ of 0.2 , the culture was shifted to $42{ }^{\circ} \mathrm{C}$ for $90 \mathrm{~min}$. As the control, the unstressed culture was used, and once it reached an $\mathrm{OD}_{600}$ of 0.2 it was grown for an additional $90 \mathrm{~min}$ at $37^{\circ} \mathrm{C}$.

Total RNA was isolated using the hot acid phenol procedure as described previously (McGrath et al. 2001). Contaminating DNA was degraded using RNase-free DNase (Fermentas). The concentration and purity of the RNA preparations was then estimated by measuring the A260 and A280 with a NanoDrop ND-1000 spectrophotometer. The RNA quality and integrity was further analyzed by agarose gel electrophoresis. The absence of DNA from RNA preparations was verified by the failure to amplify a 16S rRNA gene fragment in a 30-cycle PCR using $1 \mu \mathrm{g}$ of RNA as the template. The prepared RNA was stored at $-70{ }^{\circ} \mathrm{C}$ until required for analysis.

Transcriptional analysis of the studied genes

To compare the level of transcription of the identified genes in nonstressed cells and in cells growing in different stress condition, reverse transcriptase PCR (RT-PCR) was performed as described previously using the primers specific for the identified genes and for the 16S rRNA gene (Krawczyk-Balska et al. 2012). The RT-PCR products were quantified by densitometric analysis of DNA bands on gel images using ImageQuant ${ }^{\mathrm{TM}}$ TL software (GE Healthcare, UK).

Growth in stress conditions

To examine the growth of $L$. monocytogenes strains under osmotic or acid stress conditions, overnight cultures were diluted (1:100) in BHI broth containing $0.5 \mathrm{M} \mathrm{KCl}$ or $\mathrm{HCl}$ (pH 5), respectively, and incubated with shaking at $37{ }^{\circ} \mathrm{C}$. To examine the growth under temperature stress conditions, overnight cultures were diluted (1:100) in BHI broth and incubated with shaking at $42{ }^{\circ} \mathrm{C}$. Cell growth was monitored spectrophotometrically by determining the $\mathrm{OD}_{600}$.

\section{Results and discussion}

Recently, we identified several genes of $L$. monocytogenes whose expression was upregulated in the presence of $0.09 \mu \mathrm{g} / \mathrm{ml}$ penicillin $\mathrm{G}$, which equates to 0.75 of the MIC 


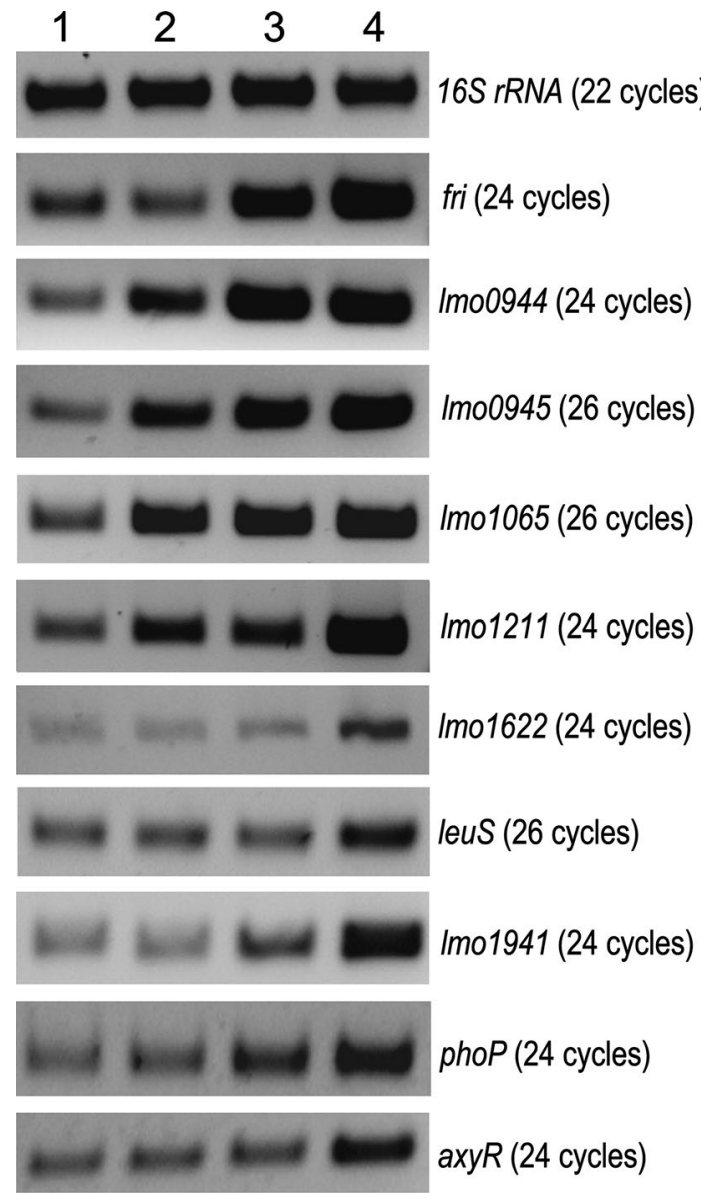

Fig. 1 Transcriptional analysis of gene expression under temperature, acid and osmotic stress conditions using RT-PCR. Total RNA was isolated from exponential phase cultures of L. monocytogenes EGD strain grown in BHI at $37^{\circ} \mathrm{C}(1)$ and exposed to $42{ }^{\circ} \mathrm{C}(2)$ or pH 5 (3) or $0.5 \mathrm{M} \mathrm{KCl} \mathrm{(4)} \mathrm{for} 90 \mathrm{~min}$ in each case. All RT-PCRs were performed three times from three separate RNA preparations. In all cases, control PCR were performed to ensure the complete removal of DNA from RNA preparations prior to reverse transcription

(minimal inhibitory concentration) value. To examine whether the expression of the identified genes was specifically induced by penicillin $\mathrm{G}$, or if it was also induced by other stresses, transcriptional analysis of these genes was performed under temperature, acid and osmotic stress conditions (Fig. 1), and their relative expression levels were quantified (Table 1). This analysis revealed that all of the selected genes were induced under osmotic stress conditions. The transcription of seven of them, namely fri, lmo0944, lmo0945, lmo1065, lmo1211, lmo1941, phoP, was upregulated under acid stress conditions. Four of the genes, namely lmo0944, lmo0945, lmo1065 and lmo1211, were upregulated under temperature stress conditions; thus, these genes exhibited an elevated level of expression under all of the stress conditions tested. Transcriptional analysis revealed that the upregulation of expression of the studied
Table 1 Relative expression levels of the studied L. monocytogenes genes

\begin{tabular}{llll}
\hline \multirow{2}{*}{ Gene } & \multicolumn{3}{l}{ Fold change in expression ${ }^{\mathrm{a}}$} \\
\cline { 2 - 4 } & $42^{\circ} \mathrm{C}$ & $\mathrm{pH} 5$ & $0.5 \mathrm{M} \mathrm{KCl}$ \\
\hline fri & $0.9 \pm 0.1$ & $2.7 \pm 0.6^{*}$ & $3.7 \pm 1.0^{*}$ \\
Imo944 & $2.9 \pm 0.1^{* *}$ & $4.8 \pm 0.7^{* *}$ & $4.8 \pm 0.9^{*}$ \\
lmo945 & $3.0 \pm 0.6^{*}$ & $3.2 \pm 0.5^{*}$ & $3.9 \pm 0.6^{*}$ \\
lmo1065 & $3.2 \pm 0.5^{*}$ & $3.1 \pm 0.3^{* *}$ & $4.7 \pm 0.8^{*}$ \\
Imo1211 & $2.4 \pm 0.4^{*}$ & $2.3 \pm 0.4^{*}$ & $4.7 \pm 0.6^{*}$ \\
Imo1622 & $1.2 \pm 0.3$ & $1.3 \pm 0.3$ & $5.1 \pm 0.4^{* *}$ \\
leuS & $1.2 \pm 0.2$ & $1.3 \pm 0.3$ & $3.4 \pm 0.9^{*}$ \\
Imo1941 & $1.1 \pm 0.2$ & $2.3 \pm 0.3^{*}$ & $5.1 \pm 0.2^{* *}$ \\
phoP & $1.5 \pm 0.4$ & $2.3 \pm 0.5^{*}$ & $5.0 \pm 0.5^{* *}$ \\
axyR & $1.2 \pm 0.3$ & $1.3 \pm 0.2$ & $3.7 \pm 0.6^{*}$ \\
\hline
\end{tabular}

${ }^{\text {a }}$ The numbers given are the relative amounts of the RT-PCR products obtained using a template of total RNA isolated from $L$. monocytogenes EGD exposed to $42{ }^{\circ} \mathrm{C}$, $\mathrm{pH} 5$ or $0.5 \mathrm{M} \mathrm{KCl}$, in comparison with the corresponding amounts for the wild-type strain grown in $\mathrm{BHI}$ broth at $37{ }^{\circ} \mathrm{C}$ without any stressors. The RT-PCR products were quantified by measuring the level of band fluorescence using ImageQuant software. Relative expression levels were normalized to the levels of 16S rRNA. Asterisks indicate significant differences according to Student's $t$-test $(* P<0.05 ; * * P<0.01)$

genes is not restricted to cell wall-acting antibiotic pressure, indicating that these genes belong to a more general stress stimulon of L. monocytogenes. Similar results concerning the cellular response of Streptomyces coelicor to antibiotics that target the cell envelope have been reported (Hesketh et al. 2011). This study clearly showed that antibiotic treatment induces changes in the expression of many genes of the heat, osmotic and oxidative stress regulons. Strikingly, in our study, the expression of all penicillin G-inducible genes was also upregulated in response to osmotic stress conditions. This finding suggests that the cell-envelope-stress response in L. monocytogenes is linked to the osmotic stress response. This observation is consistent with the results of a study on the cefuroxime stimulon of L. monocytogenes that demonstrated that the expression of highly cefuroxime-induced genes is also induced by osmotic stress (Nielsen et al. 2012).

Given the significant role of regulatory proteins in $L$. monocytogenes response to multiple stresses, the genes fri, phoP and axyR were chosen for further investigation concerning their involvement in temperature, acid and osmotic stress tolerance since these genes encode proteins with regulatory potential. For this purpose, the wild-type and $\triangle p h o P, \Delta a x y R$ and $\Delta f r i$ mutants were analyzed for their responses to temperature, acid and osmotic stress. No difference in growth rates was observed when the strains were cultured at $42{ }^{\circ} \mathrm{C}$ (data not shown). Likewise, the $\Delta p h o P$ and $\triangle a x y R$ mutants and the wild-type grew equally well in 

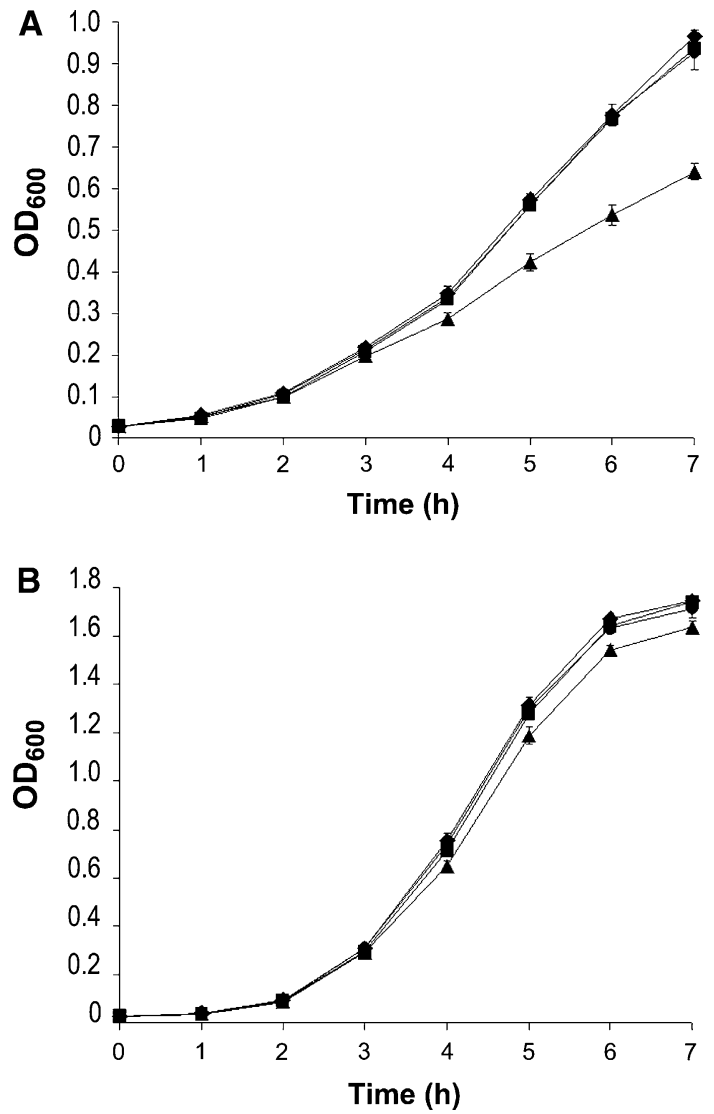

Fig. 2 Growth of wild-type L. monocytogenes EGD (filled circle), $\triangle a x y R$ mutant (filled diagonal), $\Delta p h o P$ mutant (filled square) and $\Delta$ fri mutant (filled triangle) in $\mathrm{BHI}$ broth $\mathrm{pH} 5$ adjusted with $\mathrm{HCl}$ (a) and in BHI broth supplemented with $0.5 \mathrm{M} \mathrm{KCl}$ (b). Overnight cultures were inoculated $(1: 100)$ into BHI broth supplemented with appropriate stressor, and cultures were incubated with shaking at $37^{\circ} \mathrm{C}$. Cell growth was measured spectrophotometrically by determining the optical density at $600 \mathrm{~nm}$. Error bars, standard deviations from three independent experiments

media adjusted to $\mathrm{pH} 5.0$ and in media supplemented with $0.5 \mathrm{M} \mathrm{KCl}$ (Fig. 2). Thus, the analysis revealed that the lack of phoP and axyR does not affect the adaptation of $L$. monocytogenes to temperature, acid or osmotic stress conditions. However, the growth rate of the $\Delta$ fri mutant strain was slightly reduced in comparison with that of the wildtype strain in a hyperosmotic environment, and growth of the $\Delta$ fri mutant was clearly impaired under acid stress conditions (Fig. 2). Thus, the Fri protein of L. monocytogenes was found to be involved to some extent in osmotic stress tolerance although it appears to play a minor role under these stress conditions. Similarly, increased expression of other members of the Dps family, such as Dps of E. coli, DpsA of B. subtilis and MsDps1 of Mycobacterium smegmatis, has been observed under osmotic stress conditions, which suggests the participation of these proteins in adaptation to this stress (Antelmann et al. 1997; Weber et al. 2006; Chowdhury et al. 2007), but so far they have not been shown to play a key role in osmotic stress tolerance. Interestingly, the listerial ferritin was found to play an essential role in acid stress tolerance of this bacterium. This observation is consistent with reports that mutants of E. coli lacking the Dps protein are much more susceptible to DNA strand breaks than the wild type under acidic conditions, which results in a sharp decline in dps mutant survival (Choi et al. 2000; Jeong et al. 2008).

Acknowledgments This work was partially supported by the State Committee for Scientific Research, Poland (Grant N303 033 31/0938 and Grant N N302 229738).

Open Access This article is distributed under the terms of the Creative Commons Attribution License which permits any use, distribution, and reproduction in any medium, provided the original author(s) and the source are credited.

\section{References}

Antelmann H, Engelmann S, Schmid R, Sorokin A, Lapidus A, Hecker M (1997) Expression of a stress- and starvation-induced dps/pexB homologous gene is controlled by the alternative sigma factor SigmaB in Bacillus subtilis. J Bacteriol 179:7251-7256

Begley M, Hill C, Ross RP (2006) Tolerance of Listeria monocytogenes to cell envelope-acting antimicrobial agents is dependent on SigB. Appl Environ Microbiol 72:2231-2234

Choi SH, Baumler DJ, Kaspar CW (2000) Contribution of dps to acid stress tolerance and oxidative stress tolerance in Escherichia coli O157:H7. Appl Environ Microbiol 66:3911-3916

Chowdhury RS, Gupta S, Chatterji D (2007) Identification and characterization of the dps promoter of Mycobacterium smegmatis: promoter recognition by stress specific extracytoplasmic function sigma factors SigmaH and SigmaF. J Bacteriol 189:8973-8981

Cotter PD, Emmerson N, Gahan CGM, Hill C (1999) Identification and disruption of lisRK, a genetic locus encoding a two-component signal transduction system involved in stress tolerance and virulence in Listeria monocytogenes. J Bacteriol 181:6840-6843

Cotter PD, Guinane MC, Hill C (2002) The LisRK signal transduction system determines the sensitivity of Listeria monocytogenes to nisin and cephalosporins. Antimicrob Agents Chemother 46:2784-2790

Dussurget O, Dumas E, Archambaud C, Chafsey I, Chambon C, Hébraud M, Cossart P (2005) Listeria monocytogenes ferritin protects against multiple stresses and is required for virulence. FEMS Microbiol Lett 250:253-261

Ferreira A, O'Byrne CP, Boor KJ (2001) Role of $\sigma^{\mathrm{B}}$ in heat, ethanol, acid, and oxidative stress resistance and during carbon starvation in Listeria monocytogenes. Appl Environ Microbiol 67:4454-4457

Gandhi M, Chikindas ML (2007) Listeria: a foodborne pathogen that knows how to survive. Int J Food Microbiol 113:1-15

Haikarainen T, Papageorgiou AC (2010) Dps-like proteins: structural and functional insights into a versatile protein family. Cell Mol Life Sci 67:341-351

Hesketh A, Hill C, Mokhtar J, Novotna G, Tran N, Bibb M, Hong HJ (2011) Genome-wide dynamics of a bacterial response to antibiotics that target the cell envelope. BMC Genomic 12:226

Hof H (2003) Listeriosis: therapeutic options. FEMS Immunol Med Microbiol 35:203-205 
Jeong KC, Hung KF, Baumler DJ, Byrd JJ, Kaspar CW (2008) Acid stress damage of DNA is prevented by Dps binding in Escherichia coli $\mathrm{O} 157: \mathrm{H} 7$. BMC Microbiol 8:181

Kallipolitis BH, Ingmer H, Gahan CG, Hill C, Søgaard-Andersen L (2003) CesRK, a two-component signal transduction system in Listeria monocytogenes, responds to the presence of cell wallacting antibiotics and affects $\beta$-lactam resistance. Antimicrob Agents Chemother 47:3421-3429

Krawczyk-Balska A, Lipiak M (2013) Critical role of a ferritinlike protein in the control of Listeria monocytogenes cell envelope structure and stability under $\beta$-lactam pressure. PLoS One 8:e77808

Krawczyk-Balska A, Marchlewicz J, Dudek D, Wasiak K, Samluk A (2012) Identification of a ferritin-like protein of Listeria monocytogenes as a mediator of $\beta$-lactam tolerance and innate resistance to cephalosporins. BMC Microbiol 12:278

McGrath S, Fitzgerald G, van Sinderen D (2001) Improvement and optimization of two engineered phage resistance mechanisms in Lactococcus lactis. Appl Environ Microbiol 67:608-616

Nielsen PK, Andersen AZ, Mols M, van der Veen S, Abee T, Kallipolitis BH (2012) Genome-wide transcriptional profiling of the cell envelope stress response and the role of LisRK and CesRK in Listeria monocytogenes. Microbiology 158:963-974
Olsen KN, Larsen MH, Gahan CG, Kallipolitis B, Wolf XA, Rea R, Hill C, Ingmer H (2005) The Dps-like protein Fri of Listeria monocytogenes promotes stress tolerance and intracellular multiplication in macrophage-like cells. Microbiology 151:925-933

Raimann E, Schmid B, Stephan R, Tasara T (2009) The alternative sigma factor $\sigma^{\mathrm{L}}$ of $L$. monocytogenes promotes growth under diverse environmental stresses. Foodborne Pathog Dis 6:583-591

Sabet C, Toledo-Arana A, Personnic N, Lecuit M, Dubrac S, Poupel O, Gouin E, Nahori MA, Cossart P, Bierne H (2008) The Listeria monocytogenes virulence factor InlJ is specifically expressed in vivo and behaves as an adhesin. Infect Immun 76:1368-1378

Vazquez-Boland JA, Kuhn M, Berche P, Chakraborty T, DominguezBernal G, Goebel W, Gonzalez-Zorn B, Wehland J, Kreft J (2001) Listeria pathogenesis and molecular virulence determinants. Clin Microbiol Rev 14:1-57

Weber A, Kogl SA, Jung K (2006) Time-dependent proteome alterations under osmotic stress during aerobic and anaerobic growth in Escherichia coli. J Bacteriol 188:7165-7175

Williams T, Bauer S, Beier D, Kuhn M (2005) Construction and characterization of Listeria monocytogenes mutants with in-frame deletions in the response regulator genes identified in the genome sequence. Infect Immun 73:3152-3159 